\title{
Applying the perceptions of graduates on their dental training to inform dental curricula from the perspective of occupational health.
}

SADJ June 2018, Vol 73 no 5 p343 - p347

R Moodley ${ }^{1}$, S Naidoo ${ }^{2}$, J Van Wyk. ${ }^{3}$

\begin{abstract}
Introduction: Dental education, one of the most stressful fields of study, is associated with many occupational health hazards. Clinical training is focussed on patient care and occurs under the supervision of a qualified practitioner, and is thus the most appropriate time to educate students about the prevention of occupational health problems. The study aimed to report on the reflections of dental graduates on their undergraduate training from the perspective of occupational health.
\end{abstract}

Methods: This cross sectional, descriptive study used both quantitative and qualitative methods in the collection of data from a study population comprising dentists, dental therapists and oral hygienists in KwaZulu-Natal, South Africa.

Results: The response rate was 41\% ( $n=169), 80 \%$ ( $n=138)$ and $40 \%(n=46)$ for dentists, dental therapists and oral hygienists respectively. There was little focus $(77.7 \%)$ on health and well-being of students and self-care in their dental training. Clinical work had started in the first year for $30 \%$ of the participants, and in the third year for $54.4 \%$ of the students. Undergraduate training lacked modules on occupational health, practice/business management, posture training, ergonomics and stress management.

Conclusion: The perceptions of this study population indicated a need for the inclusion of occupational health training in undergraduate dental curricula.

1. Rajeshree Moodley: $B$ Dent Ther (UKZN), MSc Dental Public Health (UWC). Lecturer, Discipline of Dentistry, School of Health Sciences, University of KwaZulu-Natal, South Africa.

2. Saloshni Naidoo: $M B C h B$ (Natal), PhD (Utrecht). Senior Lecturer, Discipline of Public Health Medicine, School of Nursing and Public Health, University of KwaZulu-Natal, South Africa.

3. Jacqueline Van Wyk: PhD.Discipline of Clinical and Professional Practice, School of Clinical Medicine, College of Health Sciences, University of KwaZulu-Natal, South Africa.

\section{Corresponding author}

Rajeshree Moodley:

Discipline of Dentistry, School of Health Sciences, University of

KwaZulu-Natal, South Africa. E-mail: moodleyra@ukzn.ac.za
Keywords: dental education, self-care, occupational health, ergonomics

\section{INTRODUCTION}

Dentistry, although regarded as a rewarding profession, is both physically and mentally challenging. Clinical practice requires a need for precision and high concentration. Dental practice is unfortunately associated with many occupational problems i.e. musculoskeletal disorders, percutaneous injuries, stress and biological hazards. Occupational health problems not only affect dental practitioners but according to the World Health Organisation, two million people die each year as a result of occupational accidents and work related illness and disease. A further 160 million new cases of work related illness occur each year. A significant 8\% of the global burden of disease from depression is due to occupational risks. ${ }^{1}$

For the purpose of the study the term "oral health practitioner" or "dental practitioner" will refer to an oral health worker, whether dentist, dental specialist, dental therapist or an oral hygienist. This study was part of a larger study investigating how curricula could possibly change to include the awareness of occupational health problems, their causes and their prevention. Participating dental practitioners were asked to reflect on their undergraduate dental training and to answer a series of both closed and open ended questions.

It is noteworthy that the first phase of the larger study has indicated that the prevalence of musculoskeletal disorders among dental health practitioners is high, dentists being identified as most affected by occupationrelated health problems. The next most prevalent affliction was percutaneous injury. ${ }^{2}$

Dental education is regarded as one of the most challenging fields of study. It is a normal requirement for students to demonstrate their achievement of many competencies prior to graduation. Clinical training is focussed on patient care and conducted under the supervision of a qualified practitioner and is thus regarded as the most appropriate time and place to educate the student about 
the prevention of occupational health problems. Dental education can draw from the Theories of Learning. This is not just transmitting information from the teacher to the learner but should recognise the different types of knowledge i.e. tacit, structured, codified, disciplinary and pedagogic. ${ }^{3}$ Tacit knowledge refers to intuitive, hard to define knowledge that is largely experience-based. The acquisition of tacit knowledge thus depends on the context and the students' personal experience. It is hard to communicate and is deeply rooted in action, commitment, and involvement. ${ }^{4}$ It is not directly taught but is demonstrated and the need for attention should be communicated to students. ${ }^{5}$ Clinical feedback should be structured, comprehensive, positive and encouraging. ${ }^{5}$ Feedback and assessment rubrics as used in dental training should therefore include consideration of posture and positioning of both the practitioner and patient.

The integrated approach to workplace health programs should include the work environment, work organisation, lifestyle and health behaviours. Ergonomics is the study of a workers' efficiency in a working environment. Ergonomics provides a framework to improve physical and organisational structures at work. ${ }^{6}$ It is argued that the dental curriculum should prepare the dental student for efficient practice in the workplace, since the training environment simulates the actual practice environment, and offers a start to healthy work-based practices. In a study of a similar nature, Thornton and colleagues concluded that preparing a student for ergonomic challenges involved recognising physical and psychosocial stress factors, then reinforcing ergonomic concepts that might be taught didactically, and training students to understand biomechanical principles and how to reduce or eliminate risk factors. ${ }^{7}$ The question may be posed: Does the curriculum in dentistry prepare our students for safe work-based practice?

This article reports on the reflections of dental graduates on their undergraduate dental training with a view to understanding the extent to which the dental curriculum had prepared them for self-care in clinical practice, and, further, to gather their input regarding the inclusion of occupational perspectives in the dental curriculum.

\section{METHODS}

This cross sectional, descriptive study used both quantitative and qualitative data collection methods to explore the perspectives of dental practitioners about their undergraduate training. The training period in dentistry in South Africa (SA) is a five year programme in comparison with dental therapy and oral hygiene, both of which extend over three years. The typical dental curriculum offers exposure to basic sciences in the first year, to diagnostics and therapeutic aspects in the second year and to the clinical sciences in the third year. The first clinical exposure for dentists was thus in their third academic year while therapists and hygienists received their first clinical exposures from the second and first years.

The study population comprised all dentists $(n=400)$, dental therapists $(n=119)$ and oral hygienists $(n=115)$ based in KwaZulu-Natal (KZN) and registered with either the South African Dental Association (SADA), South African
Dental Therapy Association or Oral Hygiene Association. All registered practitioners were invited to participate through email, telephone or physical visits to their practices. A link to the online questionnaire was emailed to all practitioners on the respective registers ( $K Z N$ branches). The researcher also attended conferences of the relative associations to distribute questionnaires and to encourage improvement in the response rate.

A self-administered questionnaire was used for data collection. The questionnaire was piloted $(n=10)$ and minor changes were made prior to the study. The questionnaire explored the nature and extent of exposure to clinical work, aspects relating to self-care and well-being and the suggestions of practitioners regarding aspects which may be considered for review in the dental curriculum. This study formed the second phase of a three- phase project for which ethical clearance had been obtained from the Humanities \& Social Sciences Research Ethics Committee (UKZN) - reference no: HSS/1490/015D.

All participants were informed of the purpose of the study through an information sheet and gave informed consent prior to participation. They were also informed of their right to withdraw from the study at any stage.

Quantitative and qualitative data were exported from QuestionPro.* Quantitative data were analysed in SPSS version 24. Frequencies and means with standard deviations were calculated for categorical and continuous variables. Qualitative data collected in response to open ended questions that explored dental curricula were entered in an Excel spreadsheet to allow for thematic analysis.

${ }^{*}$ QuestionPro Inc. (US) http//www.questionpro.com.

\section{RESULTS}

The response rate was 41\% ( $n=169), 80 \%(n=138)$ and $40 \%$ $(n=46)$ for dentists, dental therapists and oral hygienists respectively. The majority of participants were female $(n=203$; $57.5 \%$ ) and $24.6 \%$; $n=87$ ) held postgraduate qualifications (Table 1). On average the participants had been in practice

\begin{tabular}{|c|c|c|c|c|c|c|c|c|}
\hline & \multicolumn{2}{|c|}{ Dentists } & \multicolumn{2}{|c|}{$\begin{array}{c}\text { Dental } \\
\text { therapists }\end{array}$} & \multicolumn{2}{|c|}{$\begin{array}{c}\text { Oral } \\
\text { hygienists }\end{array}$} & \multicolumn{2}{|c|}{ Total } \\
\hline & $n$ & $\%$ & $n$ & $\%$ & $\mathrm{n}$ & $\%$ & $n$ & $\%$ \\
\hline Participants & 169 & 47.9 & 138 & 39.1 & 46 & 13 & 353 & 100 \\
\hline Male & 90 & 25.5 & 57 & 16.1 & 3 & 0.8 & 150 & 42.5 \\
\hline Female & 79 & 22.4 & 81 & 22.9 & 43 & 12.2 & 203 & 57.5 \\
\hline $\begin{array}{l}\text { Post graduate } \\
\text { degree }\end{array}$ & 39 & 23.1 & 41 & 29.7 & 7 & 15.2 & 87 & 24.6 \\
\hline
\end{tabular}

for 12 years and had graduated 13 years ago.

Participants were asked to reflect on the nature of their clinical work, duration of practice and typical self-care behaviour in relation to how they had been taught in the curriculum at university. The participants were asked, as experienced dental practitioners, to reflect on their training.

Table 2 provides a summary of the data pertinent to the first exposure to clinical work, the number of hours spent 
on clinical work by each group and the extent to which they worked under pressure. Also recorded were reactions to questions relating to working under time constraints and exposure to considerations of occupational health.

Participants were asked to reflect on their undergraduate dental curriculum, exploring what was lacking in their undergraduate training from the viewpoint of occupational health. The responses are summarised in Table 3, which presents the themes, frequency of response and supporting quotes.

Participants provided the following suggestions to improve dental training in the future when considering occupational health. They suggested the inclusion of:

"A subject on occupational health, not just mentioned in the clinics."

"A course on occupational health identifying effects and risks and preventative measures. Also recommendations to ensure that different procedures are imperative- avoid repetitive motions that can cause musculoskeletal damage acutely and chronically."

The most frequent suggestion related to the inclusion of ergonomics, posture, equipment and surgery design:

\begin{tabular}{|c|c|c|c|c|c|c|c|c|}
\hline & \multicolumn{2}{|c|}{ Dentist } & \multicolumn{2}{|c|}{$\begin{array}{l}\text { Dental } \\
\text { therapist }\end{array}$} & \multicolumn{2}{|c|}{$\begin{array}{c}\text { Oral } \\
\text { hygienist }\end{array}$} & \multicolumn{2}{|c|}{ Total } \\
\hline & $\mathrm{n}$ & $\%$ & $\mathrm{n}$ & $\%$ & $n$ & $\%$ & $\mathrm{n}$ & $\%$ \\
\hline \multicolumn{9}{|c|}{ 1.First exposure to clinical work } \\
\hline First year & 18 & 10.7 & 53 & 38.4 & 34 & 73.9 & 105 & 29.7 \\
\hline Second year & 59 & 34.9 & 78 & 56.5 & 12 & 26.1 & 149 & 42.2 \\
\hline Third year & 92 & 54.4 & 7 & 5.1 & 0 & 0 & 99 & 28 \\
\hline \multicolumn{9}{|c|}{ 2.The location of clinical training sites as a student (multiple responses) } \\
\hline University & 149 & 61.1 & 67 & 27.5 & 28 & 11.5 & 244 & 69.1 \\
\hline $\begin{array}{l}\text { Training cen- } \\
\text { tres }\end{array}$ & 30 & 24.2 & 73 & 58.9 & 21 & 16.9 & 124 & 35.1 \\
\hline Satellite clinics & 30 & 51.7 & 25 & 43.1 & 3 & 5.2 & 58 & 16.4 \\
\hline outreach & 31 & 45.6 & 34 & 50 & 3 & 4.4 & 68 & 19.2 \\
\hline \multicolumn{9}{|c|}{ 3.The number of hours spent on clinical work per day as a student } \\
\hline 2 to 6 hours & 127 & 75.1 & 129 & 93.5 & 41 & 89.1 & 297 & 84.1 \\
\hline $\begin{array}{l}\text { More than } 6 \\
\text { hours }\end{array}$ & 42 & 24.9 & 9 & 6.5 & 5 & 10.9 & 56 & 19.9 \\
\hline \multicolumn{9}{|c|}{ 4. Did you have to work fast? } \\
\hline Never & 13 & 7,7 & 1 & 0.7 & 5 & 10.9 & 19 & 5.4 \\
\hline Sometimes & 51 & 30.2 & 54 & 39.1 & 16 & 34.8 & 121 & 34.3 \\
\hline Often & 64 & 37.9 & 52 & 37.7 & 16 & 34.8 & 132 & 37.4 \\
\hline Always & 41 & 24.3 & 31 & 22.5 & 9 & 19.6 & 81 & 22.9 \\
\hline \multicolumn{9}{|c|}{ 5. Were you given extra time to finish your work? } \\
\hline Never & 29 & 17.2 & 22 & 15.9 & 14 & 30.4 & 65 & 18.4 \\
\hline Sometimes & 101 & 59.8 & 84 & 60.9 & 25 & 54.3 & 210 & 59.5 \\
\hline Often & 32 & 18.9 & 18 & 13 & 6 & 13 & 56 & 15.9 \\
\hline Always & 7 & 4.1 & 14 & 10.1 & 1 & 2.2 & 22 & 6.2 \\
\hline
\end{tabular}

6 . In your undergraduate training was there a focus on your health and wellbeing as a practitioner?

\begin{tabular}{|l|c|c|c|c|c|c|c|c|}
\hline Never & 81 & 47.9 & 59 & 42.8 & 18 & 39.1 & 158 & 44.8 \\
\hline Sometimes & 64 & 37.9 & 37 & 26.8 & 15 & 32.6 & 116 & 32.9 \\
\hline Often & 16 & 9.5 & 18 & 13 & 6 & 13 & 40 & 11.3 \\
\hline Always & 8 & 4.7 & 24 & 17.4 & 7 & 15.2 & 39 & 11 \\
\hline
\end{tabular}

\begin{tabular}{|c|c|c|c|c|c|c|c|c|}
\hline \multicolumn{9}{|c|}{$\begin{array}{l}\text { 7. Did you learn about how to take care of yourself as a qualified } \\
\text { practitioner from an occupational health perspective? }\end{array}$} \\
\hline Never & 83 & 49.1 & 50 & 36.2 & 18 & 39.1 & 151 & 42.8 \\
\hline Sometimes & 53 & 31.4 & 37 & 26.8 & 12 & 26.1 & 102 & 28.9 \\
\hline Often & 24 & 14.2 & 21 & 15.2 & 10 & 21.7 & 55 & 15.6 \\
\hline Always & 9 & 5.3 & 30 & 21.7 & 6 & 13 & 45 & 12.7 \\
\hline \multicolumn{9}{|c|}{ 8. Did you learn about self-care? } \\
\hline Never & 81 & 47.9 & 39 & 28.3 & 19 & 41.3 & 139 & 39.4 \\
\hline Sometimes & 59 & 34.9 & 50 & 36.2 & 11 & 23.9 & 120 & 34 \\
\hline Often & 22 & 13 & 22 & 15.9 & 10 & 21.7 & 54 & 15.3 \\
\hline Always & 7 & 4.1 & 27 & 19.6 & 6 & 13 & 40 & 11.3 \\
\hline
\end{tabular}

"Ergonomics and how to purchase equipment ...some guidelines"

"Ergonomics and occupational hazards in the dental profession"

The inclusion of health and wellbeing was also frequently suggested and participants suggested the inclusion of information and recommendations on exercises to prevent musculoskeletal disorders in dental curricula.

Others thought that stress management programs and self-care should form part of the dental training programme. They also expressed the need for training sessions to model and include discussions on how to work in a multidisciplinary team.

\section{DISCUSSION}

The study sample consisted of dentists, dental therapists and oral hygienists. A post graduate degree had been attained by $23.1 \%$ of dentists in this sample. This percentage was higher than the percentage reported in 2011 among participants in a Brazilian study $(5.5 \%){ }^{8}$

As noted in the results, $30 \%$ of the participants had started clinical work in their first year. Among the dentists 54.4\% had started clinical work in the third year. Early clinical exposure is beneficial and has a positive impact on students. Ali et al. noted that whilst on one hand early clinical exposure eliminates stress by spreading out the workload and clinical training through the curriculum, it tended to inflate the first year. ${ }^{9}$ Students already had to deal with anatomy, physiology and life sciences during their first academic year. ${ }^{9}$ Early clinical contact was supported by McHarg and Kay as it gives students the opportunity to learn the affective dimension of learning, the "heart" skills. ${ }^{10}$

The results of the study indicate that selfcare as recommended for inclusion in the curriculum would benefit dental students. It is relevant to note that $77.7 \%$ of participants responded that there was little or no focus 
Table 3: Reflection on undergraduate training $(n=353)$

\begin{tabular}{|c|c|c|}
\hline Themes & $\begin{array}{l}\text { Frequency } \\
\quad(\mathrm{n} ; \%)\end{array}$ & Quote/supporting evidence \\
\hline $\begin{array}{l}\text { 1.Occupational } \\
\text { health module }\end{array}$ & $\begin{array}{c}81 ; \\
(22.9 \%)\end{array}$ & $\begin{array}{l}\text { "Module on occupational health, it's benefits and the importance to us as health care practitio- } \\
\text { ners" (participant } 67407103 \text { - dental therapist) } \\
\text { "A subject on occupational health, not just mentioned in the clinics" (participant } 67300632 \text { - } \\
\text { dental therapist) } \\
\text { "an occupational health course pertaining to dental health practitioners would have made a world } \\
\text { of difference if included in our curriculum" (participant } 73662819 \text { - dentist) }\end{array}$ \\
\hline $\begin{array}{l}\text { 2.Practice/ } \\
\text { business } \\
\text { management }\end{array}$ & $\begin{array}{c}80 \\
22.6 \%\end{array}$ & $\begin{array}{l}\text { "How to manage a practice, and work faster; private practice is extremely stressful, none of us was } \\
\text { prepared for it; a lot of mental strain; university needs to teach us about business management rather } \\
\text { than psychosocial orientation... What a waste of a module" (Participant 61065806- dental therapist) }\end{array}$ \\
\hline 3.Posture & $\begin{array}{c}71 \\
20.1 \%\end{array}$ & $\begin{array}{l}\text { "Correct working posture was included in the pre-clinical lab and sometimes when working in } \\
\text { the clinic but more intense sessions should be done in occupational health. Only daily posture is } \\
\text { covered minimally but no one talks about repetitive posture - causes and impact on your body, } \\
\text { detail preventative measures of such risks to your health" } \\
\text { (Participant 73719952- dental therapists) }\end{array}$ \\
\hline $\begin{array}{l}\text { 4. How to deal with } \\
\text { stress? }\end{array}$ & $\begin{array}{c}60 \\
16.9 \%\end{array}$ & $\begin{array}{l}\text { "Two year diploma, as the course is too intensive and the time constraints to finish such a vast } \\
\text { scope of practice leaves room for increased occupational health hazards for an already stressed } \\
\text { student"(Participant } 67459422 \text {-oral hygienist) }\end{array}$ \\
\hline $\begin{array}{l}\text { 5.Ergonomics/ } \\
\text { surgery design }\end{array}$ & $\begin{array}{c}45 \\
5.3 \%\end{array}$ & $\begin{array}{l}\text { "Ergonomics related to our field and correct posture" (participant } 73873685 \text { - dentist) } \\
\text { "Clinical training should include proper ergonomics training" (Participant } 68607868 \text { - dental } \\
\text { therapist) } \\
\text { "ergonomics and how to purchase equipment ....some guidelines" (participant } 73675011 \text { - } \\
\text { dentist) }\end{array}$ \\
\hline $\begin{array}{l}\text { 6. Multidisciplinary } \\
\text { approach }\end{array}$ & $\begin{array}{c}40 ; \\
11.3 \%\end{array}$ & $\begin{array}{l}\text { "Occupational physical health hazards, sitting positions, input from chiropractors, occupational } \\
\text { therapists or physiotherapists on how to minimize/ eliminate problems such as muscle pain, } \\
\text { pinched nerves, spasms etc." (Participant } 66100397 \text { - dentist) }\end{array}$ \\
\hline $\begin{array}{l}\text { 7. Exercise and } \\
\text { fitness }\end{array}$ & $\begin{array}{c}32 \\
9.0 \%\end{array}$ & $\begin{array}{l}\text { "An inclusion on how to take care of yourself as a clinician is important, for example there } \\
\text { should be an emphasis on good posture and guiding exercise routines that a dental clinician } \\
\text { can carry out to alleviate pain and to prevent any long term physical damage"( Participant } \\
61443711 \text { - dental therapist) }\end{array}$ \\
\hline
\end{tabular}

on their health and wellbeing in their undergraduate training. When dental practitioners reflected on the dental curriculum, $71.7 \%$ stated that almost no attention was directed to discussion on how they should take care of themselves in practice from an occupational health perspective. Seventy- three percent of the participants had never or perhaps sometimes, learnt about self-care (Table 2). Self-care programs that focus on coaching and stress management have the potential to benefit dental students. ${ }^{11,12}$ Greeson et al. in their intervention study introduced a skills building and self-care workshop for medical students, which included mind-body skills with relaxation exercise and meditation. Students tracked their progress on their smartphones and it was revealed that $100 \%$ of the group benefitted from the program with $70 \%$ starting to take care of themselves and $70 \%$ having started practicing mind-body skills in the week. The researchers in the Greeson study concluded that the program taught students resilience to stress. ${ }^{12}$

Proposing inclusion of occupational health as a topic into the dental curriculum is not new and has been suggested by many studies. ${ }^{13-17} \mathrm{~A}$ cross sectional study among dental students in Croatia led to the introduction of a module entitled "Occupational diseases in dental medicine". The course was introduced in the 6th semester just before preclinical training. This was a multidisciplinary course and included lectures and practical sessions. The researchers in this Croatian study concluded that students should be aware of occupational health diseases and prevention prior to starting independent practice. ${ }^{18}$ Participants in the current study indicated that a course in occupational health should be included in the dental curriculum with emphasis on both preclinical and clinical training.

The inclusion of dental ergonomics and awareness as curricular topics was also suggested by participants in the current study and this recommendation has been backed by many studies. ${ }^{19,21}$ Ergonomics includes the kind of work done, the tools used in practice and the working environment. The aim is to find a good fit between the practitioner and the work condition and to ensure that all practitioners are safe during work and not be prone to work based injuries. The prevention and reduction of MSD among dental practitioners should be included in dental training and teaching ergonomics is recommended by participants. Gupta et al. in their systematic review concluded that ergonomic training in dental schools is a good prevention strategy. He went on to further recommend it as a separate course that should be periodically assessed. ${ }^{20}$ Instrument handle size, width and weight affects muscle load and pinch force, therefore knowledge of these factors when selecting instruments is important for young dentists as this will reduce the prevalence of hand symptoms. ${ }^{22}$

The participants in this study reported a lack of exposure to stress management during their undergraduate training and they thought that the topic needed proper exposure in the dental curriculum. Stress among dental students is not uncommon. ${ }^{23,24}$ When one draws from the Pau et al. study one realises that not only is stress management needed in the curriculum but also required is the development of emotional intelligence so that the coping mechanism of dental students is improved. ${ }^{24}$ 
Dental training institutions should collaborate with educational experts to have a curriculum aimed at the psychological health of students. ${ }^{13}$

Practice management and financial training were a concern as participants reflected on undergraduate training. Many practitioners enter private practice with minimal financial planning experience and practice management skills. Baldwin et al. in their research stated that dental graduates enter practice already burdened with debt and the undergraduate curriculum does not have sufficient input in administrative training and in running a practice..$^{15}$ Poor practice management and lack of financial planning adds to the stress levels of dental practitioners.

Developing information into knowledge requires understanding of the four different types of knowledge and how people learn, as discussed in the introduction. ${ }^{25}$ The theory of occupational health principles, self-care, correct posture and health and safety can be discussed in lectures but it is irrelevant if not practiced and reinforced in clinical training. This is explained well by researchers McHarg and Kay who describe learning about bicycles as explicit knowledge and learning how to ride a bicycle as tacit knowledge. ${ }^{25}$ Thus clinical training requires a positive attitude, constant reinforcement, attention to detail and repetition to promote learning.

Limitations of this study were that it was conducted in KZN and was not a national study so it has limits affecting its generalisability. The participants had trained at various institutions in South Africa and the curriculum is not standard throughout SA.

\section{CONCLUSION}

This study provided insights into the perceptions of dental graduates of their exposure to occupational health in dental curricula. The study population indicated a need for the inclusion of occupational health training in the undergraduate dental curriculum. It also provided relevant indicators of the curriculum changes needed to make it more amenable to the inclusion of occupational health issues. Further research into the impact of stress is needed in SA. It would be prudent to engage with multiple stake holders to inform dental education considering occupational health.

\section{References}

1. WHO. Healthy workplaces: a model for action: for employers, workers, policy-makers and practitioners. 2010.

2. Moodley R, Naidoo S, van Wyk J. The prevalence of occupational health-related problems in dentistry: A review of the literature. Journal of occupational health. 2018;60(2):111-25.

3. McHarg J, Kay E. The anatomy of a new dental curriculum. British dental journal. 2008;204(11):635.

4. Nonaka I. A dynamic theory of organizational knowledge creation. Organization science. 1994;5(1):14-37.

5. Fugill M. Teaching and learning in dental student clinical practice. European Journal of Dental Education. 2005;9(3):131-6.

6. Punnett L, Cherniack M, Henning R, Morse T, Faghri P, Team C-NR. A conceptual framework for integrating workplace health promotion and occupational ergonomics programs. Public Health Reports. 2009;124(4_suppl1):16-25.

7. Thornton LJ, Stuart-Buttle C, Wyszynski TC, Wilson ER. Physical and psychosocial stress exposures in US dental schools: the need for expanded ergonomics training. Applied Ergonomics. 2004;35:153-7.
8. Alexandre PCB, da Silva ICM, de Souza LMG, de Magalhaes Câmara V, Palacios M, Meyer A. Musculoskeletal disorders among Brazilian dentists. Archives of environmental \& occupational health. 2011;66(4):231-5.

9. Ali K, Zahra D, McColl E, Salih V, Tredwin C. Impact of early clinical exposure on the learning experience of undergraduate dental students. European Journal of Dental Education. 2017.

10. McHarg J, Kay EJ. Designing a dental curriculum for the twenty-first century. British Dental Journal 2009;207(10):5.

11. Mafla A, Villa冈Torres L, Polychronopoulou A, Polanco H, Moreno囚Juvinao V, Parra囚Galvis D, et al. Burnout prevalence and correlates amongst Colombian dental students: the STRESSCODE study. European Journal of Dental Education. 2015;19(4):242-50.

12. Greeson JM, Toohey MJ, Pearce MJ. An adapted, four-week mind-body skills group for medical students: Reducing stress, increasing mindfulness, and enhancing self-care. Explore: The Journal of Science and Healing. 2015;11(3):186-92.

13. Ahmad MS, Yusoff MMM, Razak IA. Stress and its relief among undergraduate dental students in Malaysia. Southeast Asian Journal of Tropical Medicine and Public Health. 2011;42(4):996.

14. Alsabaani NA, Awadalla NJ, Abualiat ZM, Alshahrani MA, Alqahtani AM, Alshuraym MM. Occupational ocular incidents in dentists: a multicentre study in southwestern Saudi Arabia. International dental journal. 2017.

15. Baldwin P, Dodd M, Rennie J. cross-infection control: Young dentists-work, wealth, health and happiness. British dental journal. 1999;186(1):30-6.

16. Eren $\mathrm{H}$, Huri M, Bagis N, Basibuyuk O, Sahin S, Umaroglu $\mathrm{M}$, et al. BURNOUT AND OCCUPATIONAL PARTICIPATION AMONG TURKISH DENTAL STUDENTS. SOUTHEAST ASIAN JOURNAL OF TROPICAL MEDICINE AND PUBLIC HEALTH. 2016;47(6):1343-52.

17. Moodley R, Naidoo S. The prevalence of musculoskeletal disorders among dentists in KwaZulu-Natal. South African Dental Journal. 2015;70(3):98-103.

18. Matoš K, Jurec Z, Gali凶 I, Vodanovi凶 M. Education on occupational health and health related habits among dental students in Croatia. Acta stomatologica Croatica. 2016;50(1):49-57.

19. Gopinadh A, Devi KNN, Chiramana S, Manne P, Sampath A, Babu MS. Ergonomics and musculoskeletal disorder: as an occupational hazard in dentistry. The journal of contemporary dental practice. 2013;14(2):299.

20. Gupta A, Ankola AV, Hebbal M. Dental ergonomics to combat musculoskeletal disorders: a review. International Journal of Occupational Safety and Ergonomics. 2013;19(4):561-71.

21. Smith CA, Sommerich CM, Mirka GA, George MC. An investigation of ergonomic interventions in dental hygiene work. Applied Ergonomics. 2002;33(2):175-84.

22. Dong H, Loomer P, Barr A, LaRoche C, Young E, Rempel D. The effect of tool handle shape on hand muscle load and pinch force in a simulated dental scaling task. Applied Ergonomics. 2007;38(5):525-31.

23. Polychronopoulou A, Divaris K. Dental Students' Perceived Sources of Stress: A Multi-Country Study. Journal of Dental Education. 2009;73(5):9.

24. Pau A, Croucher R, Sohanpal R, Muirhead V, Seymour $\mathrm{K}$. Emotional intelligence and stress coping in dental undergraduates-a qualitative study. British dental journal. 2004;197(4):205-9.

25. McHarg J, Kay EJ. The anatomy of a new dental curriculum. British Dental Journal. 2008;204(11). 